\title{
El valor de la patología ósea en la identificación personal, a propósito de un caso con espondilitis anquilosante.
}

The importance of osseus pathology in personal identification, relevant to a case with ankylosing spondylitis.

\section{A. Ramírez Álava y cols. Cuad Med Forense 2000; 22:52-58}

En el presente artículo, los autores revisan la importancia de la patología ósea como factor de identificación personal en antropología forense a raíz de un caso de espondilitis anquilosante. En el caso expuesto, se trataba de establecer la identificación de un individuo del que se conocía el lugar del enterramiento, si bien presentaba la particularidad de ser un panteón familiar donde reposaban los restos de varios familiares allí inhumados. Debido al conocimiento del padecimiento en vida por parte del sujeto problema de una patología ósea con importantes alteraciones esqueléticas, como es la espondilitis anquilosante, pudo concluirse una identificación personal positiva tras el pertinente estudio antropológico.

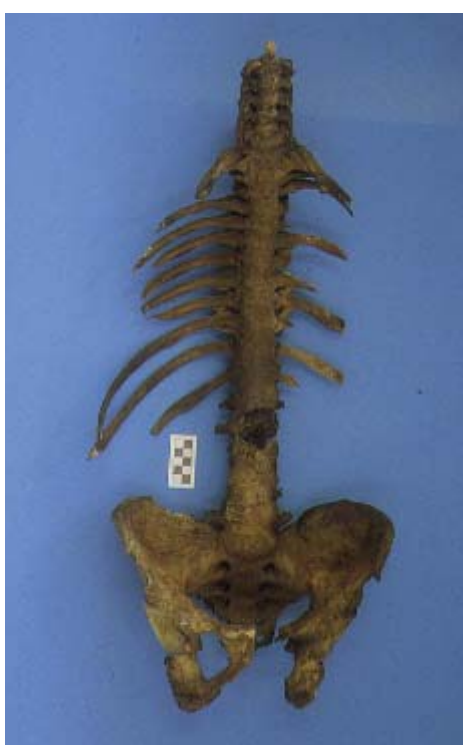

Figura 1.- Columna vertebral "en caña de bambú".

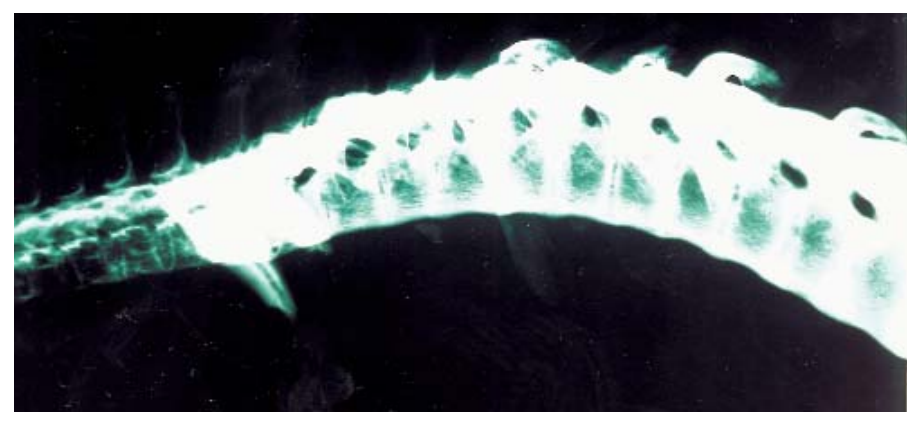

Figura 2.- Radiografía lateral de dicha columna vertebral. Se observa rectificación cervical y sinostosis homogénea en cuerpos vertebrales.

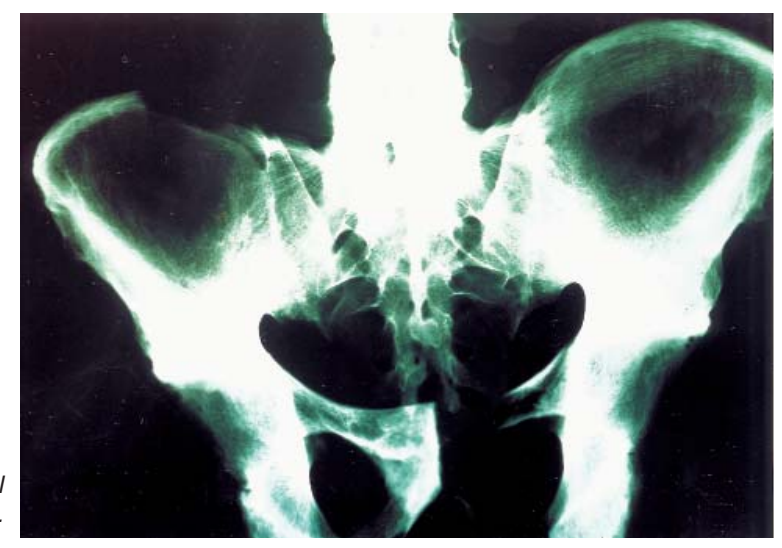




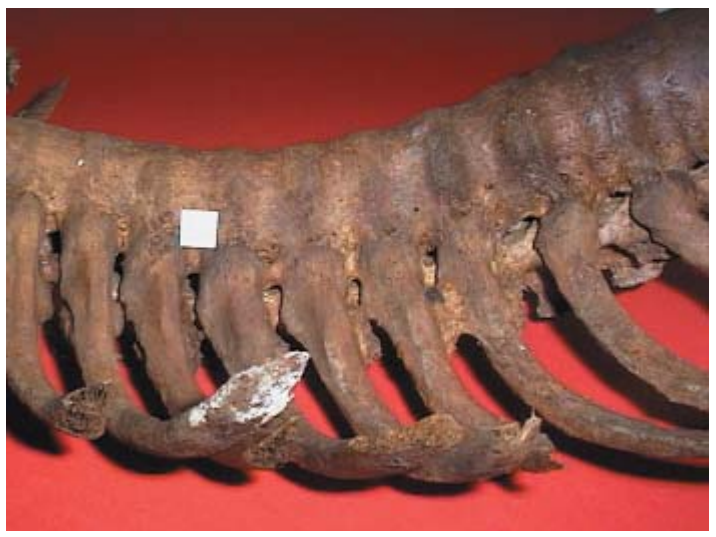

Figura 4.- Detalle de la columna vertebral donde se aprecia claramente la fusión intervertebral y en las articulaciones costovertebrales.

Figura 5.- Radiografía A-P de columna vertebral con fusión generalizada de articulaciones costo-vertebrales.
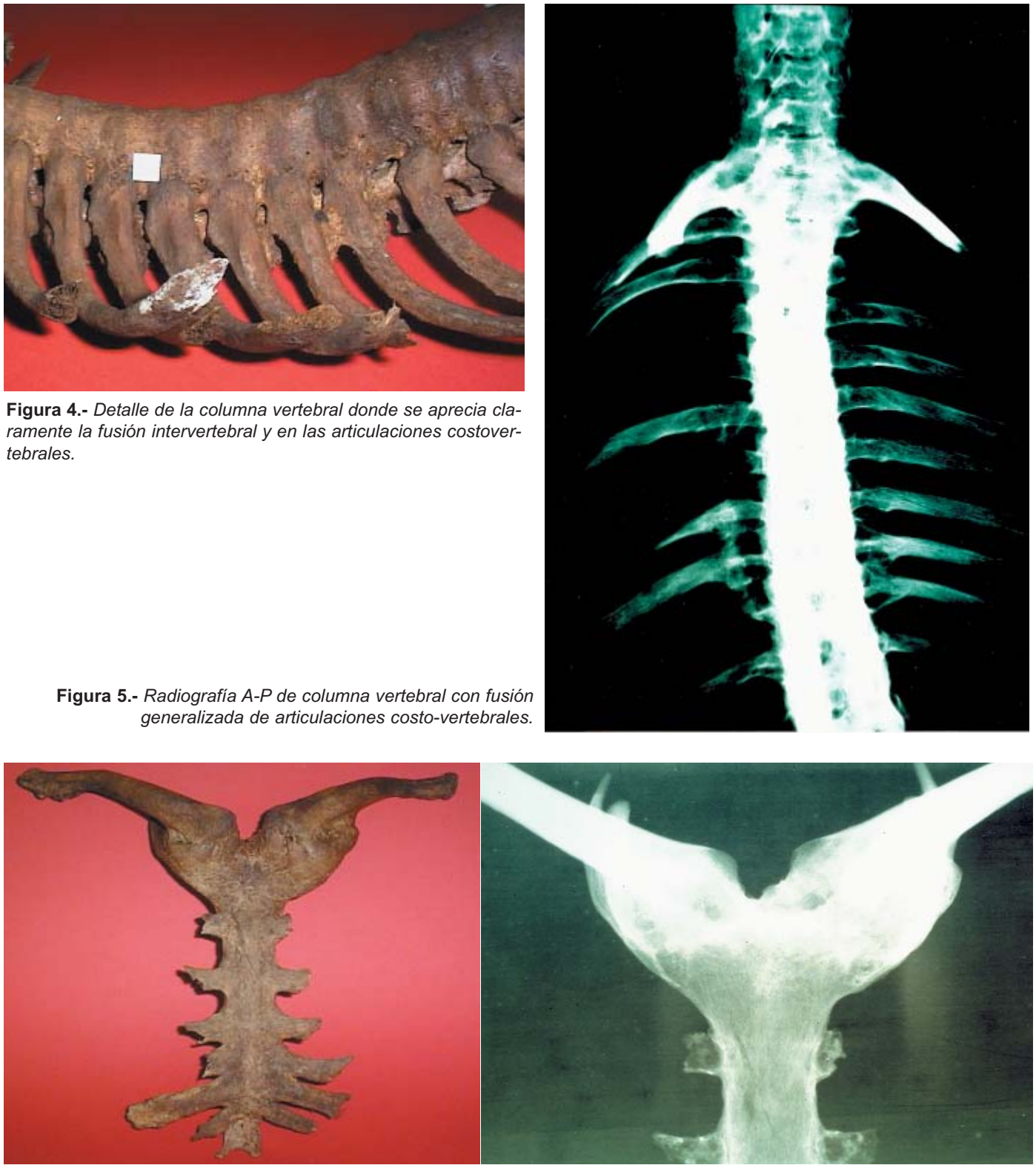

Figuras 6 y 7.- Se observa la sinostosis esternoclavicular completa con una exuberante neoformación ósea.

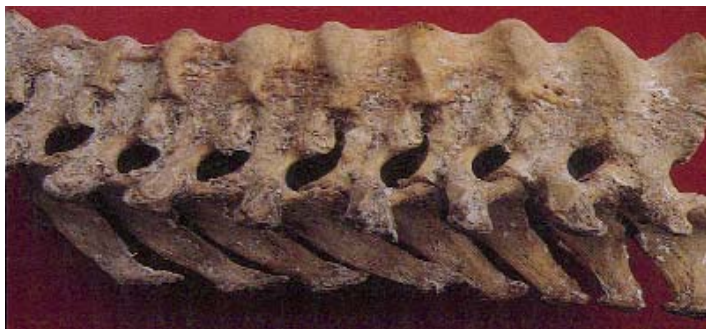

Figura 8.- Sinostosis por osificación del ligamento longitudinal anterior; hallazgo típico de la enfermedad de Forestier-Rotés Querol. 